\title{
NBW-vermogensrecht 25 jaar
}

\author{
Prof. mr. H.J. Snijders*
}

\section{Alweer een beschouwing over een jubileum van het NBW-vermogensrecht}

Wij plegen te zeggen dat op 1 januari 1992 het Nieuw Burgerlijk Wetboek (NBW) werd ingevoerd. We bedoelen dan het vermogensrecht van de Boeken 3, 5 en 6 plus enige delen van Boek 7 BW. Zeker voor de lezers van dit maandblad spreekt dat welhaast voor zichzelf. Laten wij echter de codificatie van het burgerlijk recht geen onrecht aandoen door te negeren dat de Boeken 1, 2 en 8 al in werking traden in 1970, 1976 respectievelijk 1991 en dat daarna nog de Boeken 4 (2003) en 10 (2012) ingevoerd werden. Laten we ook niet vergeten dat Boek 7 onder het motto 'zwaan, kleef aan' in de loop der jaren enorm is uitgegroeid en dat er 'al' een voorontwerp van Boek 9 bestaat. ${ }^{1}$ Dit gezegd zijnde is er alle reden om dat in 1992 ingevoerde NBW-vermogensrecht nader te bezien.

Alle reden? Is er niet meer dan genoeg jubileumliteratuur over dit wetboek? Volstaan niet artikelen zoals bijvoorbeeld die in de Rode draad '20 jaar Nieuw BW' van Ars Aequi (AA 2012), het WPNR-themanummer '25 jaar Nieuw Burgerlijk Wetboek' (WPNR 2017/7133), het als lofzang bedoelde boek Vifftig weeffouten in het $B W^{2}$ en een aantal NJB-artikelen naar aanleiding van een recent jubileumcongres? ${ }^{3}$ Misschien wel, misschien niet. De lezer oordele zelf na lezing van deze op uitnodiging geschreven korte jubileumbijdrage, die bestaat uit enige algemene observaties en persoonlijke meningen over de betekenis van ons NBW en dan met name het NBW-vermogensrecht (hierna omwille van de eenvoud ook: (N)BW), nu en in de toekomst. Naar het zich laat aanzien wordt die toekomst met name door Europa bepaald; daarover ook enkele beschouwingen mede ter bepaling van de positie ten aanzien van de vraag naar een eventueel Europees BW anno 2018.

Prof. mr. H.J. Snijders is honorair hoogleraar Burgerlijk recht en burgerlijk procesrecht aan de Universiteit Leiden.

Dank aan mijn promovenda mr. Gitta N. Veldt en mijn student-assistent Nick du Bois voor hun commentaar bij een eerdere versie van dit artikel.

1. Vgl. hierover bijv. D.J. Visser \& H. Spath, Waar is boek 9 dan gebleven?, AA 2017, p. 381 e.v. en eerder W. Snijders, Twintig jaar nieuw BW, AA 2012, p. 946 e.v., i.h.b. p. 946 en noot 2.

2. Friso van de Pol e.a. (red.), Vijftig weeffouten in het BW, Nijmegen: Ars Aequi Libri 2017 (waarin ook de in noot 1 genoemde beschouwingen zijn opgenomen).

3. Het gaat hier om het jubileumcongres dat het ministerie van Justitie en Veiligheid organiseerde op 20 november 2017. Naar op de kopijdatum van mijn bijdrage verluidt, zullen de bijdragen voor dat congres vrij snel na dit artikel gepubliceerd worden in het NJB. Van de concepttekst van de congresvoorzitter, prof. mr. T. Hartlief, kon ik al kennisnemen.

\author{
2 Codificatie van burgerlijk recht, van vloed naar eb \\ en van eb naar vloed
}

Geen land in de wereld heeft in en rond de tweede helft van de twintigste eeuw een zo krachtige codificatiegolf op het gebied van het burgerlijk recht doorgemaakt als het onze. Dat geldt met name ook voor het vermogensrecht. Niet voor niets kwalificeerde Van der Grinten het op 1 januari 1992 ingevoerde $\mathrm{BW}$ in de woorden van Horatius als een monumentum aere perennius (id est: sterker dan brons). Gezegd moet wel worden dat het vuurwerk in de oudjaarsnacht van 1991/1992 door het Nederlandse volk niet werd afgestoken ter ere van de invoering van het nieuwe BW, zoals al vrij snel daarna aannemelijk werd gemaakt door de rechtshistoricus Lokin. ${ }^{4}$ Toch doet dat aan de betekenis van het NBW niets af. Codificaties van burgerlijk recht zullen vermoedelijk nooit hot issues worden. De waan van de dag is vreemd aan codificaties en politiek zijn zij vaak nauwelijks interessant. Voor leken, onder wie lekenjournalisten, zijn artikelen uit wetboeken dikwijls taaie, ontoegankelijke stof, die pas tot leven komt zodra de rechter deze gaat toepassen in maatschappelijk spannende zaken. Het gaat bij ons BW (niettemin) om een onmiskenbaar knappe uitwerking van ons burgerlijk recht, zowel in de diepte als in de breedte. Dit nieuwe BW vormt dan ook, het zij herhaald, een monumentum aere perennius.

Naar zijn aard heeft een wetboek ook gebreken en het kost ook geen moeite om die op te sommen. Ik zal mij daarvan in deze bijdrage grotendeels weerhouden. Uitzonderingen bevestigen ook hier de regel. Bovendien biedt reeds de in paragraaf 1 aangeduide literatuur een toereikend overzicht van gebreken, al is een gebrek voor de een wel eens een aanwinst voor de ander. Het wetboek leent zich dan ook telkens weer voor verbeteringen, maar - al weer - wat de een als een verbetering beschouwt, ziet de ander als een stap terug. Bovendien geldt dat een kathedraal - en dat is ons BW in figuurlijke zin bepaald - naar haar aard vrijwel doorlopend restaurationsbedürftig is. Dat de vele tientallen auteurs van een kloeke bundel als Vijftig weeffouten in het $B W$ inderdaad hoogstens vijftig al dan niet vermeende weeffouten in dat BW weten bloot te leggen, vormt dan ook een geruststellende gedachte, zeker nu het niet om schokkende weeffouten lijkt te gaan en de foutenanalyse heeft plaatsgevonden over de volle breedte van het BW van Boek 1 t/m Boek 10.

Al met al laat zich zonder nadere adstructie, maar wel onder verwijzing naar die in paragraaf 1 genoemde literatuur betogen

4. J.H.M. Lokin, Waarin ook een klein volk groot kan zijn, NTBR 1992, afl. 1, p. 2 e.v. 
dat de beoordeling van ons nieuwe BW royaal positief uitvalt. Het is dan ook niet voor niets dat dit BW het burgerlijk recht van vele andere landen ingrijpend heeft beïnvloed en aldus beschouwd kan worden als een van de belangrijkste immateriele exportproducten van Nederland. Te noemen vallen bijvoorbeeld (wat inmiddels heet) het Caribisch deel van ons Koninkrijk, Suriname, Rusland, Wit-Rusland, Kazachstan, Oekraïne, Georgië en andere GOS-landen, de Baltische staten, Albanië, Mongolië en China. ${ }^{5}$

Toch is de betekenis van het BW wel wat teruggedrongen door invoering van de ene na de andere bijzondere regeling. Alleen al in de 'Gouden Kluwer' vinden we (onder de tab 'Aanverwante regelgeving Burgerlijk Wetboek') zeventig bijzondere regelingen en dan gaat het nog slechts om zorgvuldig op relevantie voor studenten in het verplichte rechtenonderwijs geselecteerde regelgeving.

Daar komt bij dat het BW van binnenuit erodeert, met name door implementatie van EU-recht. Zo wordt de derdenbescherming van art. 3:86 BW bijvoorbeeld begrensd door art. 3:86a lid $1 \mathrm{BW}$, bepalende:

'Artikel 86 kan niet worden tegengeworpen aan een lidstaat van de Europese Unie of aan een andere staat die partij is bij de Overeenkomst betreffende de Europese Economische Ruimte die een roerende zaak opeist, die krachtens de nationale wetgeving van die staat een cultuurgoed is in de zin van artikel 2, onder 1, van Richtlijn 2014/60/EU van het Europees Parlement en de Raad van 15 mei 2014 betreffende de teruggave van cultuurgoederen die op onrechtmatige wijze buiten het grondgebied van een lidstaat zijn gebracht en houdende wijziging van Verordening (EU) nr. 1024/2012 (PbEU 2014, L 159), mits die zaak in de zin van die richtlijn op onrechtmatige wijze buiten het grondgebied van die staat is gebracht.'

$\mathrm{Nu}$ kan men menen dat juist door implementatie van bepalingen van EU-recht in het BW de codificatie van het burgerlijk recht wordt versterkt, maar bij een zo weinig zeggende, ontoegankelijke tekst als die van art. 3:86a lid $1 \mathrm{BW}$ is die versterking beperkt, en dat is niet de enige bepaling waarvoor dit geldt (maar 'beter iets dan niets' kan men zeggen; ik kom hier dadelijk nog op terug).

Daarnaast zien we implementatie van EU-recht in ons BW door middel van artikelen die wel veelzeggend en toegankelijk zijn, maar op gespannen voet staan met andere artikelen in het BW. Zie bijvoorbeeld art. 7:55 BW, dat bepaalt:

'Een overdracht ter nakoming van een financiëlezekerheidsovereenkomst tot overdracht is geen overdracht tot zekerheid of een overdracht die de strekking mist het goed na de overdracht in het vermogen van de verkrijger te doen vallen in de zin van artikel 84 lid 3 van Boek 3. De regels betreffende pandrecht zijn op een zodanige overeenkomst

5. Vgl. ook Hartlief in zijn nog te verschijnen artikel en H.J. Snijders, Eduard M. Meijers, het Nederlands BW en de wereld, AA 2010, p. 44 e.v. en de uitvoering daarvan niet van toepassing of overeenkomstige toepassing.'

Daar staat weer tegenover dat implementatie onder verwijzing naar de Europese regelgeving zelf in ieder geval nog de structuur en het stelsel van het gecodificeerde nationale recht in stand houdt en ook de broodnodige helderheid kan brengen in de verhouding tussen dat EU-recht en het nationale BWrecht. Een confrontatie zoals art. 7:55 BW die met art. 3:84 BW aangaat, is vanuit dit perspectief bezien relatief niet heel ernstig.

Eenzelfde soort argumentatie pleit voor opname van regelgeving in ons $\mathrm{BW}$ in plaats van regeling in een bijzondere wet.

$\mathrm{Al}$ met al is er dus alle reden voor een tegenbeweging die ons BW weer van eb naar vloed helpt. Beter allerlei BW-bepalingen met links naar bijzondere regelingen van Europese huize dan bijzondere regelingen die geheel loszingen van de bakermat van ons burgerlijk recht. Wat voor het Europese recht geldt, laat zich tevens voor ander internationaal en ook nationaal recht betogen (vergelijk bijvoorbeeld art. 3:86b respectievelijk 3:86a lid 2 BW).

\section{Ons vermogensrecht in de toekomst, BW of ECC?}

Moeten we na dit alles dan denken aan een BW 3.0? Toch niet zo gek om in snelle tijden als de onze een wetboek eens in de 25 jaar te hercodificeren, ook al hebben we het via allerlei wetswijzigingen redelijk bijgehouden? Er zijn diverse redenen die voor en tegen een dergelijke operatie pleiten. De meest valide reden contra is, dunkt mij, ook een heel constructieve: het wordt tijd voor een Europees BW, een European Civil Code (ECC). Bepaald geen sinecure, maar het momentum lijkt nu wel daar. Daarover nu enkele beschouwingen.

De spanning tussen common law en civil law wordt in de EU binnenkort nagenoeg weggenomen. $\mathrm{Na}$ de Brexit is de weg naar een Europese codificatie van het burgerlijk recht beter begaanbaar. Dat geldt zeker ook voor het vermogensrecht. Waarom is die Brexit van belang? Natuurlijk vanwege de omstandigheid dat na de Brexit alle grote EU-staten civil law countries zijn, die over een BW beschikken. Voor bijna alle kleinere EU-staten geldt hetzelfde. Een verdere ontwikkeling van vloed naar eb is voor het gecodificeerde burgerlijk recht van al die landen geen welkom perspectief. De toegankelijkheid, inzichtelijkheid en coherentie van het burgerlijk recht worden nu al ernstig op de proef gesteld en dat wordt alleen maar erger en erger. Een ECC zou zo kunnen worden ingericht dat deze ruimte biedt voor aan- en invulling met specifieke nationale regelgeving, zoals op een lager niveau nu ruimte bestaat voor aan- en invulling van ons BW met decentrale nationale regelgeving.

Het momentum wordt natuurlijk niet alleen bepaald door die Brexit. De EU-regelgevingsmachine is een themageoriënteer- 


\section{Maandblad \\ Vermogensrecht}

de, vrijwel ongebreidelde broedmachine geworden van min of meer ad-hocoplossingen voor specifieke onderwerpen, variërend van pakketreizen tot retailbeleggingsproducten. Langzaam maar zeker is deze machine zich tegen zichzelf aan het keren. Er ontstaat een rechtsmoeras met het systematisch niveau van een alfabetisch register. De regels komen niet meer over, laat staan de uitleg die daaraan door Europese en nationale rechters wordt gegeven. Een centrale Europese codificatie van burgerlijk recht zou dit probleem in belangrijke mate kunnen ondervangen. Bovendien zou de Europese regelgever zich bij het ontwerpen van nieuwe regelingen eerder genoopt voelen die af te stemmen op de alsdan als magnum opus te beschouwen ECC. De toegankelijkheid, inzichtelijkheid en coherentie van het privaatrecht op nationaal en supranationaal niveau zouden hiermee weer aan terrein winnen. Tevens zou uiteraard van de gelegenheid gebruik kunnen worden gemaakt gebreken in de nationale wetboeken zo veel mogelijk weg te nemen en het privaatrecht in het licht van nieuwe maatschappelijke en technologische ontwikkelingen een facelift te geven, ook al is daar op nationaal en Europees niveau al het een en ander aan gedaan (men denke bijvoorbeeld aan de implementatie van allerlei elektronische-communicatiemechanismen zoals e-commerce en de elektronische handtekening).

Daar komt nog bij dat de Europese regelgever steeds meer gebruik lijkt te maken van verordeningen (direct werkende regels, die niet in ons BW geïmplementeerd mogen worden) in plaats van richtlijnen (die nu juist wel, althans op enigerlei wijze, in ons nationale recht geïmplementeerd moeten worden, waardoor de kans op verschillen tussen de uiteindelijk geldende rechtsregels in de lidstaten groter wordt), ook op het terrein van het vermogensrecht. ${ }^{6}$

Een Europese codificatie kan bovendien profiteren van de huidige stand van IT. Velen raadplegen regelgeving nog slechts online. Hoe gemakkelijk is het dan om links in een ECC op te nemen naar specifieke regelingen. Rond die ECC-artikelen zou ook gemakkelijker dan voorheen Europees, maar ook vooral nationaal rechtspraakrecht inzake de uitleg van die bepalingen in beeld kunnen worden gebracht. Regelgeving van wetgeverszijde valt al bijna niet meer te overzien, voor rechtspraakrecht geldt dat ook gespecialiseerde juristen niet meer kunnen nagaan hoe buitenlandse (hoogste) rechters Europese regelgeving interpreteren. Wat de Rechtbank Midden-Gelderland vindt van een regel, zien wij in Nederlandse pleitnota's nog wel terug, maar wat het Bundesgerichtshof of de Cour de cassation ervan vindt, blijft veelal onbesproken.

Zie hier reeds een viertal factoren die evenzovele aanwijzingen vormen voor de gedachte dat een Europees BW nu op meer steun moet kunnen rekenen dan ten tijde van eerdere funda-

6. Vgl. in dit verband Ruben de Graaff \& Dorine Verheij, Europese verordeningen en Nederlands vermogensrecht, AA 2017, p. 988 e.v. mentele debatten over dit onderwerp. ${ }^{7}$ Voldoende redenen om te onderzoeken of er voor een dergelijk megaproject nu wel voldoende draagvlak is vanuit de politiek, het juridische forum en de maatschappij.

Materiaal als basis voor een Europees BW, dat gestalte zou kunnen krijgen in de vorm van een EU-verordening, is er stellig voldoende. Te denken valt met name aan het Draft Common Frame of Reference (DCFR), ${ }^{8}$ talloze (mede) civielrechtelijke verordeningen en richtlijnen, sets van transnationale principles, recente hervormingen van nationaal recht, zoals die van het Franse verbintenissenrecht, en niet in de laatste plaats ons Nederlandse BW, dat ook al veel invloed heeft gehad op het DCFR.

Voldoende redenen bovendien om de ervaringen met onze codificatie bij het zoeken naar dat draagvlak voor een Europees BW in te brengen. De bezwaren die wel tegen een (her)codificatie van ons burgerlijk recht zijn aangevoerd, laten zich gemakkelijk weerleggen op basis van de ervaringen met datzelfde BW.

Steeds meer verordeningen bevatten vermogensrechtelijke regels. Het gevaar van legisme, dat wel werd aangevoerd tegen het NBW, heeft zich niet gerealiseerd. Niet alleen bevat dat NBW veel open normen, wat onmiskenbaar ook zou gelden voor een ECC, maar bovendien heeft de Hoge Raad waar nodig afstand genomen van de tekst van het wetboek. ${ }^{9}$ Die open normen hebben de discussie over het gezag van het BW ten opzichte van het gezag van de rechtspraak en ook de discussie over de redelijkheid en billijkheid versus de wettekst tot tamelijk academische aangelegenheden gedegradeerd. Men hoeft maar te denken aan het vonnis in de Urgenda-zaak ${ }^{10}$ en men ziet wat de burgerlijke rechter met open normen vermag, daargelaten of dat vonnis rechtens wel juist is en daargelaten of ingrijpen van de rechter in het klimaatbeleid nu wel zo wenselijk is. Onder die open normen nemen art. 6:2 lid 2 en 6:248 lid 2 BW wel een heel prominente plaats in. Zij stellen de overige wettelijke bepalingen buiten spel, voor zover toepassing daarvan onaanvaardbaar zou zijn uit het oogpunt van eisen van redelijkheid en billijkheid (te denken valt bijvoorbeeld aan

7. Zie voor die eerdere debatten bijv. K. Gutman, The Constitutional Foundations of European Contract Law: A Comparative Analysis, Oxford: Oxford University Press 2014, D. Schmid, (Do) We Need a European Civil Code (?), Annual Survey of International \& Comparative Law 2012, p. 263 e.v., de literatuur opgenomen in het overzicht van A.L.B. Colombi Ciacchi \& E.A.G. van Schagen, Van een optioneel kooprecht naar een volledig geharmoniseerd online én offline digitaal kooprecht?, NTBR 2016/22, noot 11 en eerder bijv. de bijdragen in het NJB d.d. 2 november 2007 van A.S. Hartkamp (NJB 2007/2007), M.W. Hesselink (NJB 2007/2008), E.H. Hondius (NJB 2007/2009) en J.M. Smits (NJB 2007/2010), vervolgd door Jacobien W. Rutgers (NJB 2007/2227).

8. Zie hierover in dit tijdschrift bijv. P.C.J. De Tavernier \& J.A. van der Weide, Naar een Europees Burgerlijk Wetboek? Het Draft Common Frame of Reference (DCFR), MvV 2011, p. 121 e.v.

9. Vgl. bijv. Ton Hartlief in zijn een dezer maanden te verschijnen NJB-artikel naar aanleiding van bovengenoemd congres.

10. Rb. Den Haag 24 juni 2015, ECLI:NL:RBDHA:2015:7145, AB 2015/336 m.nt. Ch.W. Backes. 


\section{Maandblad}

de saillante toepassing van die beperkende werking van de redelijkheid en billijkheid in de mesothelioomrechtspraak, waarbij werd voorzien in doorbreking van de wettelijke verjaringstermijn voor mesothelioomslachtoffers). ${ }^{11}$ Vergelijk bijvoorbeeld ook art. 3:13 BW over misbruik van bevoegdheid, dat eenzelfde soort functie heeft. Dergelijke bepalingen zou een ECC ook kunnen bevatten.

Een Europese (her)codificatie hoeft ook geen dure aangelegenheid te zijn. Van het NBW is wel voorspeld dat er een forse prijskaart aan zou hangen, daar is echter niets van gebleken. Zelfs van de voorspelling dat de Staat op kosten zou worden gejaagd door de in art. 3:30 BW gecreëerde staatsaansprakelijkheid voor fouten in het kadaster en de openbare registers is niets terechtgekomen.

Dat het een zaak van lange adem zou worden, ligt wel voor de hand. Reeds ons NBW vroeg om een incubatietijd van tot nu toe zeventig jaar (1947-2017). Beperken we ons tot het algemeen vermogensrecht, dat in 1992 werd ingevoerd, dan praten we nog over 45 jaar. De Europese wetgever kan echter wel profiteren van de ervaringen die in en na ons codificatieproces met het NBW zijn opgedaan, waardoor het codificatieproces efficiënter zou kunnen lopen. Bovendien ligt er al een knap DCFR, dat vergelijkbaar is met de voorontwerpen voor de BW-boeken, ander hierboven vermeld materiaal nog daargelaten. Een vliegende start is nu, anders dan toen, dus wel mogelijk. En toch, veel tijd zou een dergelijke codificatie zeker kosten - vide de aftocht van het EU-voorstel voor een kooprechtverordening. ${ }^{12}$ Ongetwijfeld kost het project zelfs zoveel tijd dat simultaan schier eindeloos veel Europese regelgeving over deelonderwerpen op ons zal blijven afkomen. Dat continue separate snipperwerk zou omgekeerd wel weer kunnen prikkelen tot voortgang met het codificatieproces.

Een punt van aandacht wordt nog gevormd door de gevolgen die een ECC kan hebben voor de rechtspleging. Onze civiele rechtspleging heeft niet zichtbaar geleden onder de invoering van een nieuw BW. Veel recht bleef in 1992 hetzelfde, zij het anders verpakt, met name ook door codificatie van 'rechtspraakrecht'. Bovendien werd er door de burgerlijke rechter onder het oude BW al geanticipeerd op het nieuwe en onder het nieuwe geretrocipeerd op onder het oude BW ontwikkelde rechtspraakrecht. In dit opzicht is een Europese codificatie toch van een ander niveau. Uniformering van het recht van de lidstaten gaat onvermijdelijk gepaard met toch soms belangrijke inhoudelijke veranderingen ten opzichte van het recht van

11. Verwezen moge hiervoor worden naar de uitwerking in H.J. Snijders, Redelijkheid en billijkheid in het vermogensrecht van het Burgerlijk Wetboek voor en na 1992, AA 2012, p. 771 e.v. Zie voorts recent bijv. P.S. Bakker, De receptiefunctie van de redelijkheid en billijkheid, WPNR $2017 / 7133$.

12. Voorstel voor een verordening van het Europees Parlement en de Raad betreffende een gemeenschappelijk Europees kooprecht d.d. 11 oktober 2011, COM(2011)635, waarover bijv. 'Het gemeenschappelijk Europees kooprecht', MvV 2012, afl. 7/8 (themanummer) en A.L.B. Colombi Ciacchi \& E.A.G. van Schagen 2016. de respectieve lidstaten. Bovendien zou men zich kunnen voorstellen dat een ECC nog meer zand in de machine van de rechtspleging veroorzaakt, doordat er nog meer prejudiciële vragen aan het Hof van Justitie van de Europese Unie (hierna: HvJ EU) worden gesteld. ${ }^{13}$ Dat is niet uit te sluiten. Te bedenken valt wel dat de regelgevingsmachine van de EU ook bij gebreke van een EU-codificatie gewoon doorgaat en dat er bij gebrek aan inzichtelijkheid en coherentie van die almaar aangroeiende lappendeken, ook meer prejudiciële vragen aan het HvJ EU te verwachten zijn. Anders gezegd: het probleem van het zand in de machine van de rechtspleging vraagt sowieso om een herijking van de rechterlijke organisatie, met inbegrip van een supranationaal college als het HvJ EU. Dit aspect dient hier nu verder terzijde te blijven, evenals de problematiek van de verhouding tussen het HvJ EU en het Europees Hof voor de Rechten van de Mens.

Een ander aandachtspunt vormt nog de omstandigheid dat de Europese wetgever in het algemeen geen onderscheid maakt tussen privaatrechtelijke en publiekrechtelijke regelgeving. Dat probleem laat zich met enige moeite attaqueren door de Europese regelgever zelf: hij kan beslissen of een bepaling al of niet in de ECC thuishoort ('met enige moeite', nu niet altijd duidelijk zal zijn in hoeverre een bepaling privaatrechtelijke rechtsgevolgen heeft of kan hebben).

Kortom, al met al voldoende reden om wederom een Europese codificatie van het burgerlijk recht te overwegen, mede in het licht van ons NBW.

13. Vgl. ook W. Snijders 2012, p. 954 